\title{
ANTOINE BERMAN, LEITOR DO ROMANTISMO ALEMÃO
}

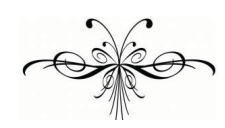

SiMONE PETRY

Resumo: O presente ensaio apresenta preliminarmente o projeto de pesquisa $A$ tradução como obra: relações entre a leitura Bermaniana do conceito romântico de obra de arte e sua reflexão sobre tradução, que tem como objetivo principal estudar a noção de tradução como obra, nos termos em que essa noção é desenvolvida no contexto das reflexões de Antoine Berman, com ênfase na discussão de seus pressupostos críticos e teóricos - como manifestação de uma visão particular da crítica e da obra de arte no contexto do Romantismo alemão.

Palavras-chave: Antoine Berman; tradução; crítica literária; Romantismo alemão.

\begin{abstract}
This essay is a preliminary presentation of a research project entitled Translation as work of art: Antoine Berman's reading of the romantic concept of work of art and his reflections on translation. The main objective of that study is to investigate the notion of translation as a work of art, pursuant to the terms in which this notion is developed in the context of Antoine Berman's reflections, emphasizing the discussion of its critical and theoretical assumptions - as a manifestation of a particular view of literary criticism and of the work of art in the context of German Romanticism.
\end{abstract}

Keywords: Antoine Berman; translation; literary criticism; German Romanticism.

\section{Um início de conversa}

$\mathrm{N}$

a França, entre as décadas de 1960 e 1970, ganhava contornos um debate ético e político impulsionado por uma crítica à ambiguidade de certa tendência no comportamento francês, caracterizada pela contradição de uma (pseudo)abertura ao estrangeiro: um distanciamento entre aquilo que proclamava o discurso político e o real destino dos refugiados e dos imigrantes. Essas discussões giravam em torno de temas desde sempre problematizados nos mais diversos discursos e contextos; porém, considera-se que a partir dessa época, nos discursos ditos modernos, eles encontraram seu próprio lugar enquanto questão, como, por exemplo, as discussões voltadas à relação com o outro e com o próprio. Buscava-se, assim, especialmente no ca- 
so do contexto francês, uma maneira de se tornar possível a conciliação entre o discurso sobre os direitos universais e a marginalização do estrangeiro.

Uma das consequências dessa postura etnocêntrica foi a crescente dificuldade na recepção de expressões culturais não francesas no país. Por conta disso, despontaram inúmeras publicações críticas desse intenso etnocentrismo, como resultado de pesquisas das mais diversas áreas das ciências humanas. Interessa-me destacar, neste ensaio, especialmente a produção intelectual relacionada à crítica e à teoria literária de expressão francesa, por apresentar, de forma entrelaçada ao movimento que esbocei até aqui, um movimento de retomada do primeiro Romantismo ${ }^{1}$ alemão. Esse foi centralmente marcado por um novo interesse nas obras de Friedrich Schlegel (1797-1800) e de Novalis (1798), interesse que renasce, em grande parte, após o resgate, na França, dos estudos da tese de doutorado de Walter Benjamin, publicada na Alemanha em 1919.

Benjamin, ao concentrar sua discussão no conceito de crítica de arte elaborada pelos pensadores do Romantismo, coloca em primeiro plano a obra de Schlegel, com destaque para a noção de filosofia cíclica; sua reflexão se desenvolve a partir do reconhecimento da necessidade do homem por sempre se reencontrar e que, por isso, "ne cesse de sortir de lui, afin de chercher et de trouver le complément de son être le plus intime dans la profondeur de celui d'autrui. Le jeu de la communication et du rapprochement est l'occupation et la force de la vie [...]." (Schlegel, 1978[1800], p. 290-1) Schlegel apresenta através dessa reflexão a necessidade que teria uma nação de encontrar no outro, no estrangeiro, ou melhor, de encontrar na experiência do, e com o, estrangeiro a sua renovação, a sua atualização, principalmente por se tratar de um processo de formação cultural ${ }^{2}$ - como reconhecido interesse de uma Alemanha então em construção. Justifica-se, portanto, o interesse de pensadores contemporâneos, críticos do etnocentrismo, pelas ideias desenvolvidas durante o período do Romantismo alemão.

O francês Antoine Berman, conhecido como tradutor e teórico da tradução, estava mergulhado nesse mesmo cenário. Sua tese de doutoramento, intitulada L'épreuve de l'étranger - Culture et traduction dans l'Allemagne romantique (1984), pode ser considerada como uma contribuição a esses debates. Do mesmo modo que seus contemporâneos, esse pesquisador irá se inspirar no pensamento romântico para sustentar sua tese, apoiando-se especialmente no conceito da Bildung, que, segundo ele, entre outras possibilidades, pode ser compreendida como uma espécie de auto-processo, em que um mesmo se desdobra ao ir em direção a um outro (estrangeiro) e retornar a si mesmo, visando, com isso, atingir sua plena dimensão. Revela-se, assim, a natureza circular e alternante desse processo, que o conceito alemão de experiência, ou, de experiência do estrangeiro, interpreta perfeitamente (Berman, 1984, p.74). Berman, nesse

\footnotetext{
${ }^{1}$ Doravante apenas Romantismo, o mesmo valendo para os termos romântico e românticos, pois trataremos aqui fundamentalmente da noção de crítica de arte elaborada nesse contexto (Romantismo alemão). "O romantismo tardio não possui nenhum conceito de crítica estética unitário e teoricamente bem delimitado, neste contexto, no qual o primeiro romantismo encontra-se só ou com direito de precedência, será possível utilizar sem risco de equívoco o simples termo romântico.”(Benjamin, 1993, p.19)

2 Essa reflexão manifesta uma das características do processo da Bildung, conceito que fundamenta o discurso de Schlegel bem como o discurso de grande parte dos pensadores envolvidos no contexto romântico. Por esse motivo, trata-se de um dos conceitos mais importantes para a formação da cultura alemã do final do séc. XVIII.
} 
texto, utiliza como mote para desenvolver sua reflexão a tradução, ou melhor, sua reflexão tem como base a questão da tradução ${ }^{3}$ (daí o seu trabalho, atualmente, ser circunscrito como teórico da tradução e ter sido praticamente restrito ao âmbito dos Estudos da Tradução). Ele reconhece na tradução um dos agentes mais importantes da Bildung, em decorrência da função mediadora do estrangeiro nesse processo. Segundo diz, foi principalmente através do fazer tradutório que surgiu a percepção, no contexto intelectual alemão, de que "[...] plus une communauté s'ouvre à ce qui n'est pas elle, plus elle a accès à elle-même." (p.58)

A partir disso, no desdobramento do seu discurso, Berman procura atualizar as reflexões elaboradas pelos românticos, principalmente aquelas que têm a marca de um trabalho infindável pela busca de uma compreensão daquilo que seria a essência do processo de criação, com foco na criação literária. Foi através desse movimento, segundo esse pesquisador, que os pensadores alemães davam conta dos ideais do programa romântico: "unir philosophie et poésie, faire de la critique une science et de la traduction un art." (p.112) Amparado por essas reflexões, o autor fortalece seus argumentos em defesa de um espaço não etnocêntrico para a tradução e de um novo modo de refletir o fazer tradutório, em concomitância com uma postura ética, política e filosófica emergentes em seu tempo e espaço. Para tanto, propõe que se recupere uma história da tradução ${ }^{4}$, visando possibilitar, a partir dessa primeira tarefa, um redimensionamento da reflexão sobre o fazer tradutório contemporâneo, de modo que essa reflexão possa se definir e se situar por si mesma. A tradução, com isso, passaria a ser discutida a partir do seu próprio fazer. Consequentemente, também começa a ser compreendida como movimento crítico. Ou ainda, a tradução, neste caso, seria elevada à segunda potência, como abertura ao seu próprio infinito, uma tradução da tradução. Para Berman, muito próximo dessa leitura estava a do movimento da crítica de arte dos românticos alemães. Segundo ele, os românticos definem que "comprendre une ouevre, c'est donc la situer dans le Tout de l'art et de la littérature, montrer son essence symbolique, qui est de signifier [...], ce Tout et l'Idée même de l'art. C'est dégager le 'sens infini' de l'ouevre."(p.1956 , realce do autor) Assim, a partir do resgate da ideia alemã de um sentido infinito da obra, como bem observa Oliveira (2003), o pesquisador francês "nos desvela o lugar ocupado pela crítica literária no Romantismo alemão. Nesse contexto, ela é um ato de interpretação não só filológica, como filosófica." (p.257)

Considerando essas questões, apresenta-se com um ponto comum entre Berman e os pensadores do Romantismo alemão o fato de eles criticarem o domínio de um discurso pautado num modelo da Razão, que, de acordo com suas reflexões, dava vazão a um viés monológico do conhecimento, silenciando tanto a pluralidade de discursos quanto outras formas de expressão. De extrema rele-

\footnotetext{
${ }^{3}$ Nesse momento há ainda outro debate em ebulição nos meios intelectuais com o qual Berman também se envolveu intensamente, o que tratava da institucionalização acadêmica da Tradutologia, ou Estudos da Tradução.

${ }^{4}$ Para constituir uma história da tradução que alicerce sua reflexão, Berman promove uma leitura das reflexões de autores inseridos na história literária desde a Alemanha Clássica à PósRomântica - em que figuram Lutero, Herder, Goethe e sua literatura mundial, August e Friedrich Schlegel, Schleiermacher, Humboldt e Hölderlin - e desenvolve um estudo sobre o conceito de Bildung como eixo de sustentação de todo o pensamento romântico.
} 
vância para esta pesquisa que se inicia é o fato de que, ao combaterem esse paradigma, os românticos exercitaram uma crítica fundada na ideia de que a obra de arte só poderia ser considerada como tal se tivesse o poder de despertar inúmeras reflexões. Com isso, a obra constituiria um conhecimento aberto a uma multiplicidade de discursos, e não um objeto fechado, de monopólio de uma única voz. Então, ao aproximar o fazer tradutório do modo de crítica de arte promovido pelo Romantismo, Berman também desloca do conceito tradicional de tradução a ideia de que ela seja um simples movimento mecânico de transmissão de significados estáveis de uma língua estrangeira para uma língua nativa. A tradução, assim, apresenta-se enquanto uma atividade reflexionante, capaz de desvelar e reconstruir a unidade de uma obra, e também de manifestar questões identitárias relacionadas ao contexto no qual foi produzida. Sherry Simon (2001), que relaciona seu trabalho com tradução a perspectivas de viés pósestruturalista, diz que após o pensamento Bermaniano a tradução "devient um symtôme, um révélateur de la citoyenneté culturelle." (p.21)

Sendo assim, é possível compreender que para Berman a tradução enquanto crítica é prática refletida; por isso, seu produto não é mera cópia de outro, mas sim fruto de um fazer. Ela é, simultaneamente, movimento produtivo e produto. Dessarte, segundo meu entendimento, há o delineamento, nesse discurso, de uma noção de tradução como obra, para, a partir disso, ser possível rediscutir o espaço da tradução, com fins específicos para a institucionalização de uma área ${ }^{5}$, mas também para redimensionar a questão da tradução no âmbito da crítica, da teoria e da história literária.

\section{As ideias românticas desvelando questões}

É preciso ressaltar, no entanto, que L'épreuve de l'étrangér não foi o primeiro texto publicado por Berman, como se apresenta, em grande parte, nas publicações que discutem esse autor. Nem mesmo, e principalmente, trata-se do primeiro texto em que aborda questões pertinentes ao Romantismo alemão. Em 1968 - portanto, muito antes de Berman publicar sua tese e, com isso, ganhar reconhecimento como importante teórico da tradução -, foi publicado pela editora La Délirante 6 o conjunto de cartas enviadas por Berman ao poeta Fouad ElEtr, durante o ano de 1967, sob o título Lettres à Fouad El-Etr sur le Romantisme allemand. Esse texto é pouco estudado pelos leitores de Berman, especialmente pelos leitores brasileiros, e, a meu ver, nele se revelam, ou se desvelam, muitas das questões que o pesquisador francês irá discutir ao longo de toda a sua obra.

Naquelas cartas, inspirado constantemente pelos textos de Novalis, e de Schlegel por consequência, Berman começa a especular sobre algumas questões pertinentes à crítica romântica, concentrando-se mais pontualmente na teoria romântica do fragmento. Logo na primeira carta é possível perceber que Lettres à Fouad faz jus a um possível texto germinal para as ideias que o autor francês

\footnotetext{
${ }^{5}$ Um primeiro estudo de maior fôlego sobre a reflexão Bermaniana e a questão da tradução foi realizado por: PETRY, Simone Christina (2011): A noção Bermaniana de relação sob o viés Derridiano da hospitalidade. Dissertação de mestrado defendida no Programa de Pós-graduação em Letras da UFPR. Curitiba.

${ }^{6}$ Editora parisiense, inteiramente dedicada à poesia, fundada em 1967 pelo poeta Fouad El-Etr, com apoio de Antoine Berman. Fouad ainda hoje é seu diretor.
} 
irá reelaborar ao longo da sua trajetória - lembrando que, nesse momento, ele ainda não faz uso do termo tradução. Ele demonstra, inicialmente, o quanto a leitura dos textos românticos lhe provocou inquietações enquanto crítico:

[...] j'ai perdu cette tranquille sécurité des critiques qui peuvent écrire sur n'importe quoi, et sur n'importe qui, avec un égal bonheur. Ce n'est pas un mal. Ecrire sur la poésie me semble une entreprise hautement risquée. Comment écrire romantiquement sur le Romantisme, mystérieusement sur le mystère, fragmentairement sur le fragment? J'ai eu peur, soudain, de me trouver enfermé dans la prison de l'entendement et de la critique. (Berman, 1967, p.9, grifo meu)

Para além de colocar em questão uma postura crítica tradicional, considerando-a um processo aparentemente "tranquilo", pois sem autonomia, e passar a enxergá-la enquanto movimento criativo, ou, como nos termos de Schlegel, como crítica poética - tema sobre o qual Berman irá se debruçar durante toda a sua vida -, numa outra carta, o pesquisador francês também apresenta o despertar da sua atenção para o elemento 'reflexividade', que localiza tanto no pensamento de Schlegel como no de Novalis. Ele irá discorrer sobre o tratamento que esses pensadores alemães dão à noção de poésie de la poésie. Segundo Berman, essa noção, para esses românticos, não põe em discussão uma poesia filosófica, "mais [une] poésie qui met à jour ses conditions dans le poème luimême: que la poésie soit visible dans le poème, voici la poésie de la poésie. Cette mise à jour s'effectue par une 'réflexion'." (p.14) E segue esclarecendo sua leitura romântica, anunciando a necessidade de uma revisão da tradição para se construir um modo "moderno", um novo modo, de reflexão da poesia:

La poésie de la poésie, poésie à la seconde puissance, est oueverte sur son propre infini. Les Romantiques semblent annoncer ici la thèse moderne selon laquelle la poésie doit s'enfermer - ou plutôt s'enterrer - dans sa propre théorie. Le poème du poème, voilá en effet une idée très moderne. Et même un lieu commun. Mais il y a un abîme entre la réflexion considerée comme une élévation à la puissance et les formalisations arides des Modernes. (p.15)

Conforme vimos no item anterior, Berman irá apresentar leitura similar a essa quando manifesta, em L'épreuve de l'étranger, a necessidade de um novo modo para se pensar a tradução, que seja a partir do seu próprio fazer: uma tradução da tradução. A tradução visível no objeto traduzido. A tradução que irá potencializar, ou que irá manifestar os potenciais de uma obra, enquanto ela mesma é uma obra ${ }^{7}$. E, a partir disso, solicita uma teoria moderna da tradução. O autor realiza um movimento similar ao da crítica de arte romântica ao perceber a tradução como um potencializador de reflexão, questão que inicia uma aproximação entre sua noção de tradução e a noção romântica de obra. Berman chega mesmo a sugerir a substituição do termo prática (da tradução) pelo termo experiência e o termo teoria (da tradução) pelo termo reflexão, pois, desse modo, entende afastar-se de uma certa racionalidade presente nos significados tra-

\footnotetext{
${ }^{7}$ Essa noção de que a tradução abre, ou manifesta, os potencias ocultos de uma obra, é claramente uma leitura que Berman faz a partir do texto "A tarefa do tradutor", de Walter Benjamin. Benjamin diz: "Ela própria [a tradução] não é capaz de revelar, nem é capaz de instituir essa relação oculta [relação das línguas entre si]; pode, porém, apresentá-la, realizandoa em germe ou intensivamente." (Benjamin, 2011[1921], p.106)
} 
dicionais dos termos prática e teoria. Para ele, "a tradução é uma experiência que pode se abrir e se (re)encontrar na reflexão" (Berman, 2007[1985], p.18), anunciando, assim, um "desdobramento infinito" dessa reflexão, nos mesmos termos da ideia romântica de potencialização, ou como na teoria romântica da reflexão ${ }^{8}$.

\section{A tradução como obra: por uma releitura da reflexão Bermaniana}

O movimento Bermaniano apresentado sinteticamente até aqui, pode ser visto, de um modo geral, como uma tentativa de atualização da crítica através da crítica da tradução literária e do resgate do pensamento romântico. Essa reflexão culmina com a publicação póstuma do texto Pour une critique des traductions: John Donne (1995). Em Pour une critique o intuito do autor era o de elaborar uma espécie de síntese de L'épreuve de l'étranger, bem como de todas as suas análises de traduções apresentadas em seminários e publicadas em artigos. ${ }^{9}$ Por conta disso, Berman se dedica, na primeira parte do livro, a apresentar a crítica da tradução como um gênero daquilo que ele denomina a Crítica, com "C" maiúsculo. Para ele, essa Crítica engloba todas as grand critiques occidentaux a partir do século XVIII, principalmente a partir de Schlegel, o père fondateur de la critique moderne. É da intensa leitura e releitura desses grandes críticos, leitores de Schlegel e Novalis, do próprio Schlegel e de Benjamin, que Berman admite esboçar os contornos da sua crítica da tradução literária enquanto um dos tijolos do edifício dessa grande Crítica.

A noção de crítica da tradução literária elaborada nesse texto diferencia-se do que se faz tradicionalmente, porque não há, em grande parte do fazer tradicional, uma análise rigorosa das características básicas da tradução analisada, do projeto a partir do qual ela foi gerada, do horizonte do qual ela surgiu e da posição do tradutor. Esses são os três pilares que comporão o que Berman entende como um projeto de crítica produtiva: "[...] la critique est productive en ce que as tâche est de refléter [...]" (Berman, 1995, p.14-17, realce meu).

Assim, para concluir a sua ideia, desenvolvida ao longo de uma breve carreira de pesquisador, Berman chama a atenção para o fato de que sendo a tradução também um texto crítico, o objeto de análise da crítica da tradução literária é, portanto, um texto crítico como ela. Assim, tanto uma quanto a outra podem ser apenas um eco enfraquecido do texto que a origina (esse seria o tipo de crítica e de tradução produzidas com mais frequência) ou podem optar por se atualizar enquanto uma obra a altura daquela que a originou. Notadamente, há

\footnotetext{
${ }^{8}$ Segundo a leitura que dela faz Walter Benjamin, em especial a partir da "Filosofia Cíclica", de Schlegel, mas também de outros pensadores alemães. É, aliás, sobre essas bases que Benjamin define a crítica de arte do romantismo como Medium, como meio-de-reflexão, reeditando, no início do século XX, um movimento crítico que, como o dos românticos, também se voltava contra certo paradigma tradicional de razão e racionalidade, e que ainda "está particularmente aceso na pós-modernidade." (Seligmann, 1999, p. 10-11)

${ }^{9}$ Essas análises foram apresentadas no Collége International de Philosophie entre os anos de 1984 e 1989. Dentre as mais importantes destacam-se as análises de traduções de Hölderlin, Chateaubriand e Klossowski, publicadas sob o título A tradução e a letra ou o albergue do longínquo (2007[1985]), e a publicação póstuma L’Âge de la traduction - "la tâche du traducter"'(2008), organizada por Isabelle Berman em parceria com os membros da Association Antoine Berman, que reúne diversos textos escritos por Berman visando discutir a tradução do texto "A tarefa do tradutor", de Walter Benjamin.
} 
com isso uma retomada da ideia, que identifiquei anteriormente, de tradução como obra. Se a tradução representa um movimento reflexivo infinito (pensando no sentido infinito da obra para os românticos) de abertura ao outro, portanto, se ela é obra, o conceito de obra, para Berman, tal qual para os românticos, não tem uma definição tradicional: como algo de essência estável, algo primitivo que não se reproduz e que não se atualiza tal qual um objeto fechado. Portanto, é a partir dessas observações que inicio meus estudos sobre a questão Bermaniana da tradução como obra.

No Brasil, a recepção do pensamento Bermaniano se dá, principalmente, através de sua contribuição aos Estudos da Tradução. Seu trabalho faz eco no discurso de diversos pesquisadores brasileiros que têm na tradução a base de suas pesquisas. Parte desses pesquisadores se dedica a um estudo teórico e filosófíco da tradução, com interesse voltado para o entendimento de uma ética da tradução que tenha como base a ideia de abertura ao outro, ao estrangeiro, ou seja, interesse no conceito de ética da diferença, como denominação dada à proposta de ética apresentada por Berman. Outros pesquisadores concentram seus estudos no eixo da analitica da tradução conforme descrita por esse autor, e tomam, em alguns casos, esse pensamento como uma proposta de método do traduzir. Por conta desse último caso, atualmente o texto mais citado nas pesquisas brasileiras sobre tradução tem sido A tradução e a letra ou o albergue do longínquo ${ }^{10}$, por se tratar de um espaço em que Berman procurou explicitar e exemplificar seu trabalho de análise de traduções literárias. Porém, vale lembrar, que a proposta de Berman não é a de elaborar um método no sentido tradicional do termo. O autor procura, inclusive, fugir do termo método, esclarecendo seu projeto de crítica como uma forma de abordagem das traduções (p.12). Para ele, na tradução, movimento de produção e produto não se desvinculam durante a reflexão. Sua proposta é a de "uma retomada reflexiva da experiência que é a tradução e não uma teoria que viria descrever, analisar, e eventualmente reger essa atividade" (Berman, 2009[1989], p.347). Dessa maneira, olhar para os três eixos que Berman designa como pilares para a reelaboração de uma "teoria moderna" da tradução talvez devesse ser um ato mais atento aos preceitos românticos, à diferença daquilo que vem sendo feito até então.

Acredito que esse movimento de leitura da proposta Bermaniana, voltado apenas para questões específicas da história, da teoria e da crítica da tradução, se dê, em parte, por conta de um olhar mais preocupado em demarcar um território institucional para os Estudos da Tradução. Pois, muitas vezes, a tradução ainda é vista como uma atividade menor, uma simples transferência de signos e significados, e de realização quase mecânica, e o "original", nesse âmbito, é a única "obra de arte" envolvida no processo. Ou, ainda, é uma atividade "vista [apenas] como um sub-ramo da linguística" (Bassnett, 2005[1980], p.13), carecendo, portanto, de discussões que procurem modificar urgentemente esse quadro. Naturalmente, nesse sentido, Berman contribui de modo bastante expressivo para a área, pois sua reflexão estabelece um novo espaço para a tradução no contexto contemporâneo da crítica e da teoria da tradução justamente porque vai de encontro a abordagens tradicionalistas.

\footnotetext{
${ }^{10}$ (2007[1985]): A tradução e a letra ou o albergue do longínquo. Traduzido por Marie-Hélène Torres, Mauri Furlan e Andréia Guerini. Rio de Janeiro: 7 letras.
} 
Porém, a despeito da importância do pensamento Bermaniano para os Estudos da Tradução, pode ser considerada pouco expressiva a entrada do trabalho Bermaniano no âmbito dos estudos literários. Faltam, a meu ver, pesquisas que lancem luz no fato de que esse espaço da tradução, conforme reelaborado por Berman, restabelece-se também no contexto de discussões inerentes à crítica, à teoria e à história literária. Pois, se Berman considera a tradução como um processo reflexivo, crítico e gerador de conhecimento, nos diz que o pensamento em si pode ser entendido como tradução. Assim, como bem elabora Siscar (2001, p.87), "seguindo o tipo de raciocínio de Berman, se existe uma necessidade interna da tradução de pensar a sua própria teoria, por outro lado podemos dizer que existe, para a teoria, a necessidade de pensar a sua própria condição de tradução".

Acredito, por tudo isso, que ao direcionar um novo olhar para as implicações que a noção Bermaniana de tradução como obra tem no redimensionamento do estatuto crítico e da autonomia da tradução literária, será possível obter também um campo fértil para uma rediscussão do lugar da tradução e de suas relações com a crítica, a história e a teoria literária.

Simone Petry

petry.simone@gmail.com

Doutoranda, Universidade de Campinas 


\section{Referências bibliográficas}

Benjamin, Walter (1993[1919]): O conceito de crítica de arte no Romantismo alemão. Traduzido para o português por Márcio Seligmann-Silva. $2^{\mathrm{a}}$ Ed. São Paulo: Iluminuras.

BERMAn, Antoine (1968): Lettres à Fouad El-Etr sur le Romantisme allemand. Paris: La Délirante.

(1984): L'épreuve de l'étranger: culture et traduction dans l'Allemagne romantique: Herder, Goethe, Schlegel, Novalis, Humboldt, Schleiermacher, Hölderlin. Paris: Gallimard.

(2009[1989]): “A tradução e seus discursos". Tradução de Marlova Aseff. In: Alea: Estudos Neolatinos. V.11, n.2, julho-dezembro. Rio de Janeiro: 7Letras, p. 341-353.

(1995): Pour une critique des traductions: John Donne. Paris: Gallimard.

BASSNETT, Susan (2005[1980]): Estudos de tradução. Tradução de Sônia Gehring, Letícia Vasconcellos Abreu e Paula Azambuja Rossato Antinolfi. Rio Grande do Sul: UFRGS.

Novalis (2001[1798]): Pólen: Fragmentos, diálogos, monólogo. Tradução de Rubens Rodrigues Torres Filho, $2^{\mathrm{a}}$ ed. São Paulo: Iluminuras.

OliveirA, Maria Clara Castellões de (2003): A prova do estrangeiro (resenha). In: Revista TradTerm, n. 9. p.253-260.

SCHLEGEL, Friedrich (1978[1800]): Entretien sur la poésie. Traduction de Philippe Lacoue-Labarthe et Jean-Luc Nancy. In: LACOUE-LABARTHE, Philippe; NANCY, Jean-Luc (1978): L'absolu littéraire. Paris: Éditions du Seuil. p.289-340.

(1997[1797-1800]): O dialeto dos fragmentos. Tradução de Marcos Suzuki. São Paulo: Iluminuras.

Seligmann, Marcio (1999): A redescoberta do Idealismo Mágico. In: BenJAMIN, Walter (1993[1919]: O conceito de crítica de arte no Romantismo alemão. Tradução de Márcio Seligmann-Silva. $2^{\mathrm{a}}$ Ed. São Paulo: Iluminuras. p. 09-14.

SIMON, Sherry (2001): Antoine Berman ou l'absolu critique. In.: TTR: traduction, terminologie, redaction. Vol. 14, $\mathrm{n}^{\mathrm{o}} 2 . \quad$ Em: http://id.erudit.org/000567ar. Acesso em 01/2007.

SISCAR, Marcos (2001): A dificuldade da origem. In: Revista Letras, n.56. Curitiba: Editora UFPR. p. 85-93 